\title{
An Object-oriented Workflow Modeling Schema Using Dataflow Analysis for Collaborative E-governance Platform
}

\author{
Jingrui Ju \\ Harbin Institute of Technology \\ jjrrui@sina.cn
}

\author{
Luning Liu \\ Harbin Institute of Technology \\ liuluning@hit.edu.cn
}

\author{
Yuqiang Feng \\ Harbin Institute of Technology \\ fengyq@ hit.edu.cn
}

\begin{abstract}
In the initial stage of transforming from government to governance for developing countries, collaborative e-governance platforms should be urgently established in different contexts. Though some platforms have been previously applied to various fields, researches on common basic functions analysis and across-organization business process modeling based on a suitable workflow modeling method for the platforms design and development are insufficient. Based on an explorative analysis of platform functions and their patterns, we propose a schema for egovernance platforms modeling according to an extended method of object-oriented workflow modeling using dataflow analysis. It covers a two-step process of top-level platform workflow modeling and function objection workflow modeling. In addition, a citizen appeal processing platform is taken as an example to illustrate the utility of the schema. The schema facilitates the contextualized collaborative $e$ governance platforms development with an operable method and reusable function workflow models.
\end{abstract}

\section{Introduction}

The last few decades have been characterized by an emerging transformation from 'government' to 'governance' $[1,2,3]$, which has been a primary task of the governments in most developing countries. 'Government' refers to a traditional top-down hierarchical model of exercising power and pushing information and service within a state context $[4,5]$. In contrast, 'governance' refers to a plurilateral model of steering and regulating society through laws and regulations with the collaborative effort performed by governments, citizens, communities and other societal actors [5,6,7]. E-governance platforms based-on information and communication technologies (ICTs) are viewed as a kind of regulated environment that deal with less control and involve many interactive, networked and collaborative actors [3,8,9]. Some platforms have been previously applied to various fields in developed countries, such as eDemocract party, PeerToPatent [11], Data.gov and Challenge.gov. Nevertheless, most developing countries are placed in a beginning stage. With the evolution of more complex and specialized Digital Government, a variety of contextualized collaborative e-governance platforms should be immediately established to meet contextspecial governance objectives such as emergency, social services and regulation [12].

However, there are three major challenges in designing and developing the collaborative egovernance platforms in different contexts. Firstly, in addition to one-way public service delivery promotion that efficient e-government pursues on [45], egovernance needs to involve other common basic functions like monition and assessment to realize the essential governance's characteristics of accountability, transparency and regulation according to the established platforms $[2,13,14]$. From the perspective of platform design, the common basic functions and their corresponding patterns need to be identified for the contextualized e-governance platforms.

Secondly, comparing with process-oriented egovernment that mainly focuses on inner-government business process reengineering [15], e-governance focuses on data sharing and business process collaboration across organizational boundaries with multiple external actors participating in various roles for the special governance objective. Workflow modeling provides a standard solution for managing complex processes, typically across organizational boundaries [30,31]. Though the formal method of workflow modeling using dataflow analysis (WMDA) provides a rigorous procedure for generating workflow models to reduce design errors hiding the on-building workflow models in time [18], the simultaneous dependencies analysis of all the activities and data cause the problem of resource limitation and cost optimization, especially for the complex business processes modeling. A more suitable workflow modeling method needs to be proposed for egovernance business process modeling.

Third, as an effective guideline, research on unified development architecture of e-government promotes its implementation process from national level to local level [29].The similar research is necessary but lacking in the field of e-governance. So from the perspective of platform development, a schema for collaborative egovernance platforms modeling needs to be developed, 
systematically pulling together the various disparate and partial functions and their patterns based on an effective workflow modeling method.

To address the three above challenges during the transformation for developing countries (see Table 1), firstly we identify several universal and fundamental functions and their patterns for the collaborative egovernance platforms in different contexts, including the functions of e-service, e-administration, e-monition and e-assessment $[2,8,16,17]$. Then we propose an extended method of object-oriented workflow modeling using dataflow analysis (OOWMDA), increasing the method operability and function model reusability with the integration of object-oriented principle into WMDA, both environmentally and financially [37]. Function object as a new definition is added, dividing simultaneous dependencies analysis into two steps of top-level analysis and object-level analysis. Further, workflow modeling schema is developed for the platform development based on OOWMDA, including two steps: (1) top-level platform workflow modeling based on function object dependencies using dataflow analysis; (2) function objects workflow modeling based on activity dependencies using dataflow analysis. In addition, the workflow modeling of a citizen appeal processing platform is taken as an example to illustrate the utility of the schema, which provides designers with more complete knowledge, facilitates effective communication between process analysts and platform developers, and improves speediness and correctness of platform workflow modeling.

Table 1. The transformation from government to governance

\begin{tabular}{|c|c|c|}
\hline & Government & Governance \\
\hline Participant & Government & $\begin{array}{c}\text { Government, citizen, } \\
\text { business, community and } \\
\text { other social actors }\end{array}$ \\
\hline Model & Hierarchical push & Plurilateral collaboration \\
\hline Function & $\begin{array}{c}\text { One-way public } \\
\text { service delivery }\end{array}$ & $\begin{array}{c}\text { service delivery, monition, } \\
\text { assessment and so on }\end{array}$ \\
\hline $\begin{array}{c}\text { Business } \\
\text { process }\end{array}$ & $\begin{array}{c}\text { Process-oriented, } \\
\text { inner-government }\end{array}$ & $\begin{array}{c}\text { Function-oriented, across } \\
\text { organizational boundaries }\end{array}$ \\
\hline
\end{tabular}

\section{Literature review}

\subsection{Collaborative E-governance platform}

Governance is defined as a change in the nature or meaning of government [19]. Government existed in the form of 'strong state' in the era of big government [20], and correspondingly governance exists in the form of 'self-organizing and coordinating network of societal actors' in the era of open government[6,21]. Governance needs not necessarily be conducted exclusively by governments, but conducted collectively by governments, citizens, communities and other societal actors [6,7]. E-governance is about using new information and communication technology to encourage citizen participation (all kinds of social actors are collectively referred to as citizens in this article) in the social problems solving process with strengthening interactions between governments and citizens [8,9]. Compared with e-government, citizens transform their role from the customers to the coproducers and broaden the participation scope from decision-making to policy implementation, public services delivery and monitoring with regard to egovernance $[8,22]$.

As an essential tool of implementing e-governance initiatives, collaborative e-governance platform has been a subject of study from two perspectives: functionality and practicability, while the former is the foundation. From the perspective of functionality, various digital platforms are used by governments to establish their presence and operations and interact with external citizens based on more collaboration across government organizations and greater engagement with citizens [12]. It aims at building a transparent and accountable government allowing citizens to execute their basic human right to know [23] and help to prevent corruption, which contributes to legitimacy and enhances government performance [13, 23,24]; and building a regulatory government that collaboratively administrative operation among multiple stakeholders should be monitored by both responsible executive departments and agencies in the form of internal monition [2,14,22] and citizens with real-time feedback, reporting and monitoring in the form of external monition [2]. From the perspective of practicability, many conditions are taken into account to improve citizen engagement and their relationships with government. In the process of design and implementation, collaborative e-governance platform pursues increasing access and adoption through establishing multiple channels [25], delivering personalized services and considering citizens' various digital degrees [26,27,28]; as well as improving citizens' satisfaction and trust on government based on government responsiveness, transparency and accountability [17].

Along with the Digital Government evolution toward more complexity and greater contextualization and specialization, contextualized e-governance has become the emerging tendency of e-governance research, aiming at supporting specific efforts by various context-specific units, such as countries, cities, communities and other social units, to pursue their own governance objectives [12]. IT-enabled e-governance innovation researches have mainly focused on several sectors or areas such as emergency, regulation, transport, social services, health and policing in recent years. Though the contexts and governance objectives 
are different for these collaborative platforms, the essential goals of establishing a government with the characteristics of accountability, transparency and regulation are the same in nature $[2,13,14]$. So some basic functions will be performed by the common participants in the different or same patterns. With the environmental and financial consideration, modularized and object-oriented system design and development is more suitable for collaborative egovernance platform than e-government mostly focusing on business process reengineering $[15,45]$.

\subsection{Workflow modeling}

Organizations are facing with the challenges of constantly increasing the productivity and efficiency of their complex business processes, typically across organizational boundaries [30,31]. Workflow modeling provides a standard solution for managing complex processes and a model-driven blueprint for developing information system with a description for a business process from five perspectives: functional, behavioral, informational, operational, and organizational [15,31].

Research on workflow modeling pays more attention to the model expressiveness and verification than the logical correctness [32,33]. Workflow modeling paradigms, such as Petri net and activitybased modeling, provide notations capable of expressing process specifications and capturing activity execution constraints and special process features [34], and also provide model verification to discover data errors hiding the completed workflow models only through inefficient and inaccurate simulation [35,36]. However, a workflow specification including data-flow errors may cause unexpected process interruptions and high costs to debug and fix at run time [10].

In the perspective of data-flow, the proposed dataflow framework includes data-flow specification and data-flow analysis, which can systematically discover data-flow errors in a workflow model at design time [10]. In addition, as a formal approach providing a rigorous procedure for generating workflow models, workflow modeling using dataflow analysis (WMDA) is proposed to facilitate the communication between business process analysts and technical developers with formal workflow design analysis process and discover dataflow errors hiding the on-building workflow models in time with logical data and activity dependencies analysis [18]. WMDA method promotes normalization and correctness of workflow modeling.

Unfortunately, WMDA is restricted to resource limitations and cost optimization because of the simultaneous dependencies analysis of all the activities and data when it is applied to a complex and changeable system development [18]. But objectoriented principle, allowing to define modularized architectures based on reusable and extensible components [38,39], is usually integrated into other modeling methods, such as Object-oriented Petri net, to increase the maintainability and reusability of modeling objects [40,41].Thus, a new workflow modeling method integrating WMDA and objectoriented principle would be more suitable for complex and changeable system development.

\section{Function analysis for the collaborative e- governance platform}

According to the UNESCO definition, egovernance covers three areas of e-democracy, eadministration and e-service, which operates based on citizen e-participation [16]. Along with the role transformation from customer to co-producer and the participation scope expansion from decision-making to policy implementation, public services delivery and monition [8,22], citizens are deeply involved in collaborative governance and endowed with more civil rights such as monition and assessment through realtime feedback, reporting and monitoring [2].The expression and response of e-participants' satisfaction facilitate the communication and trust building between government and citizen [17]. Meanwhile a democratic and transparent government is not only confined to opening the administrative performance and results, but also the processes of how to achieve them. To meet these requirements, the collaborative egovernance platforms in different contexts need to realize several most fundamental functions of e-service, e-administration, e-monition, and e-assessment, but may adopt different patterns (see Figure 1).

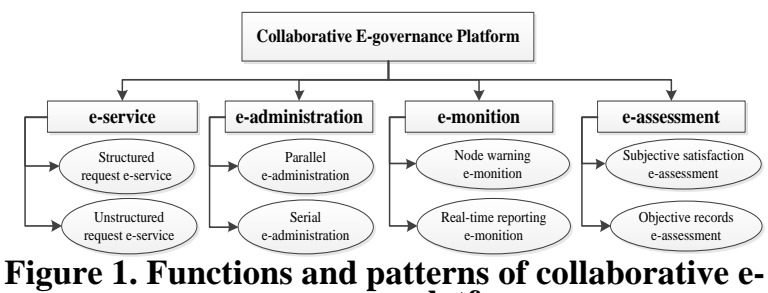
governance platform

A wide variety of interfaces like G2C or G2B eservice applications are the entrances of citizen participation[42], which can deliver structured request e-service and unstructured request e-service. The former refers to the prior identifiable and definable service that solidifies the cataloguing information and transactions in business processes, such as administrative examination and approval service [43]. Conversely, the latter refers to the prior unidentifiable and undefinable service with possible characteristics of emergency, uncertainty and diversity that hardly identifies the universal information and transactions and solidifies them in business processes, such as complaints reporting service [44]. 
E-administration is the process of handling online collaborative transactions to provide e-service by one or more providers such as public institutions, nonprofit organizations, enterprises, citizen selforganization and so on [2]. The process is either parallel or serial, while the combination of both isn't considered in this paper because it has no effect on the latter workflow modeling schema research. The former refers to the service request that can be divided into several subtasks simultaneously performed by multiple service providers with data sharing and business collaboration, and the final service output is the integration of each subtasks' output. The latter refers to the divided subtasks that must be performed according to mandatory dependencies. In other words, some subtasks' output would be certain subtasks' input.

E-monition covers internal e-monition by responsible executive departments and agencies such as the supervision department $[2,14,22]$ and external emonition by citizens with real-time feedback, reporting and monitoring [2]. The former usually employs a node warning pattern, sending warning signals of timeout or irregularity to the collaborative participants in their administrative process nodes. The latter usually employs a real-time reporting pattern, sending warning signals of unfair treatment complaint or praise to the collaborative participants during the whole administrative process.

E-assessment includes subjective satisfaction eassessment and objective records e-assessment. The former is expressing subjective satisfaction on administrative efficiency or quality by the served citizens [2], and the latter is assessing the organization performance based on the objective platform data records with a transparent and reasonable method by the assessment department.

\section{An extended method: object-oriented workflow modeling using dataflow analysis}

As the lack of formal workflow design approaches causing design errors, the WMDA method proposed by Sun and Zhao starts with dataflow specification and injects data and activity dependencies analysis into workflow design following a formal procedure, which results in efficiency in design tasks and erroravoidance in on-building workflow models [18]. However, for better meeting the demands of complex and changeable system development, we propose object-oriented workflow modeling using dataflow analysis (OOWMDA), an extended method, in this study. Contrasting with WMDA, it adds the objectoriented principle, which regards a series of continuous activities defined in WMDA as a function object and refines activity dependencies analysis into a two-step analysis of function object dependencies analysis in top level and inner-function activity dependencies analysis in object level.

Furthermore, in an extension of the related work, some key definitions of OOWMDA are enriched with new additional elements, including function object, function object data dependency and function object dependency. Figure 2 shows the basic workflow elements used in OOWMDA and a simple workflow model.

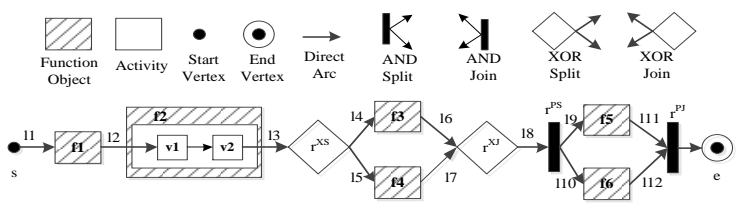

Figure 2. Workflow elements in OOWMDA and a simple workflow model example

Definition 1 (Function Object) Function object as a component of workflow model is composed of a series of continuous activities defined in WMDA. Activity linking among function objects, start activities and end activities can be seen as the simplest one. We use $f_{i}$ to present a function object.

Definition 2 (Function Object Data Dependency) Each function object $f$ takes in a set of input data $I_{f}$ composed of all input data of the including activities and produces a set of output data $O_{f}$ composed of all output data of the including activities, exclusive of the self-serve data produced and used by inner-function activities. This is called a function object data dependency for $f$, denoted as $\lambda_{f}\left(I_{f}, O_{f}\right)$.

Definition 3 (Function Object Dependency) Function object $f_{i}$ is directly dependent on another function $f_{j}$, denoted as $f_{j} \rightarrow f_{i}$, if $O_{f j} \cap I_{f i} \neq \emptyset$. If $O_{f j} \cap I^{e}{ }_{f i} \neq \varnothing$ we say that $f_{i}$ has an execution dependency on $f_{j}$, denoted as $f_{j}, \rightarrow_{\mathrm{e}} f_{i}$; otherwise, we say $f_{i}$ has a mandatory dependency on $f_{j}$, denoted as $f_{j}, \rightarrow_{\mathrm{m}} f_{i}$, if either $O_{f j} \cap I{ }_{f i} \neq \varnothing$ or $O_{f j} \cap I^{c_{i i}} \neq \varnothing$. Furthermore, $f_{i}$ is indirectly dependent on $f_{j}$ if $f_{j} \rightarrow x_{1}, x_{l} \rightarrow x_{2}, \ldots, x_{i-1} \rightarrow x_{i}$ and $x_{i} \rightarrow f_{i}$ where $x_{i}$ is some function object and $i \geq 1$, denoted as $f_{j} \Rightarrow f_{i}$.

OOWMDA method not only avoids potential workflow model design errors like WMDA but also increases method operability and model reusability. For example, as collaborative e-governance platforms involve some modularized functions with multiple patterns in different contexts, a two-step dependencies analysis procedure followed in OOWMDA is easier and less error-prone than analysing all activity dependencies simultaneously followed in WMDA for system development. Firstly, identify several essential function objects for the whole platform and analyse the function object dependencies between them for the top platform workflow modeling. Secondly, analyse the inner-function activity dependencies to design workflow models for each multi-pattern function 
object. In addition, using OOWMDA makes the addition, removal and modification of function objects flexible, which contributes to meet constantly changeable platform development requirements and is more suitable for function-oriented e-governance platform development.

\section{A workflow modeling schema for collaborative e-governance platform}

Based on the analysis of main platform functions and their corresponding patterns in different contexts (see Figure 1), a universal and formal workflow modeling schema for collaborative e-governance platform can be constructed according to OOWMDA method. The schema construction can be divided into two steps: (1) top-level platform workflow modeling based on function object dependencies using dataflow analysis; (2) function objects workflow modeling based on activity dependencies using dataflow analysis.

\subsection{Step 1: Top-level platform workflow modeling}

In the top-level platform modeling, we mainly focus on the interactions between functions to archive the collaborative governance objective, excluding the specific implementation processes for each function. Some simplest functions exist in these interaction processes, which are essential connections. These simple functions are involved in function object dependencies analysis like any other complex functions, but regarded as activities on the model representation to really highlight the fundamental functions. In order to distinguish them from actual activities, we call them bridge activities.

Based on the empirical analysis on several egovernance platforms in practice, a collaborative egovernance platform runs according to the following description generally. Firstly, citizens raise service requests through kinds of service applications interfaces. Secondly, these requests are checked automatically or artificially. If they pass the check with the consideration of service areas, corresponding administrative tasks will be produced. Otherwise, they will be refused and over. Then the administrative tasks are distributed to both service providers and service monitors. If there are some issues with the administrative processes such as timeout, irregularity and citizens' compliant or praise, corresponding warning signals will be produced by the monitors and sent to the assessment department and the service providers of problems. Otherwise, no warning information will be produced. When the administrative tasks are finished, result information is delivered to the assessors such as the assessment department and citizens. Finally, assessors complete the assessment work. Some function objects (including bridge activities) and key data are involved in this process (see Figure 3 ) and routing constraints are shown in Table 2.

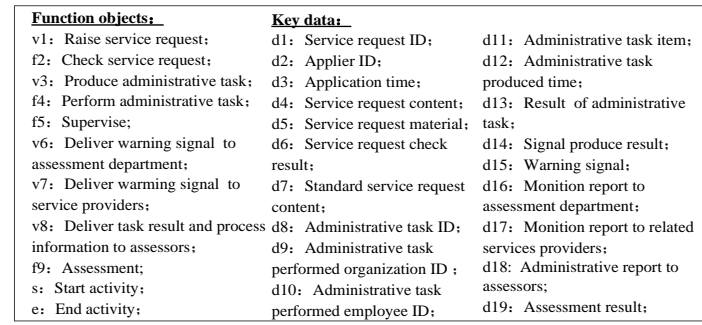

Figure 3. Function objects and key data of the toplevel platform

Table 2. Routing constraints of the top-level platform

\begin{tabular}{|l|l|}
\hline \multicolumn{1}{|c|}{ Business rule } & Routing constraint \\
\hline $\begin{array}{l}\text { If service request passes the check, the } \\
\text { administrative task will be produced } \\
\text { correspondingly. }\end{array}$ & $\begin{array}{l}\mathrm{c} 1=\{\mathrm{d} 6=\text { "Yes": } \\
\text { Execute(v3) }\}\end{array}$ \\
\hline $\begin{array}{l}\text { If service request doesn't pass the check, } \\
\text { it is over. }\end{array}$ & $\begin{array}{l}\mathrm{c} 2=\{\mathrm{d} 6=\text { "No": } \\
\text { Execute(e) }\}\end{array}$ \\
\hline $\begin{array}{l}\text { If warning signal is produced, it will be } \\
\text { delivered to the assessment department } \\
\text { and related service providers. }\end{array}$ & $\begin{array}{l}\text { c3=\{d14="Yes": } \\
\text { Execute(v6,v7) }\}\end{array}$ \\
\hline $\begin{array}{l}\text { If warning signal is produced, it is over. } \\
\text { c4=\{d14="No": } \\
\text { Execute(e) }\}\end{array}$ \\
\hline
\end{tabular}

As definition 2 extending activity data dependency to function object data dependency, we can derive unconditional, conditional, and execution data dependency for function objects correspondingly based on definition 3 in WMDA method (see Table 3 ).

Table 3. Data dependencies of the top-level platform

\begin{tabular}{|c|c|c|c|c|}
\hline $\begin{array}{c}\text { Function } \\
\text { object } \\
\text { (F) }\end{array}$ & $\begin{array}{c}\text { Unconditio } \\
\text { nal input } \\
\text { data }\left(\mathrm{I}_{f}^{u}\right)\end{array}$ & $\begin{array}{c}\text { Conditional } \\
\text { input data } \\
\left(I_{f}^{c}\right)\end{array}$ & $\begin{array}{c}\text { Executio } \\
\text { n input } \\
\text { data }\left(\mathrm{I}_{f}^{u}\right)\end{array}$ & $\begin{array}{c}\text { Output } \\
\text { data }\left(\mathrm{O}_{\mathrm{f}}\right)\end{array}$ \\
\hline $\mathrm{s}$ & $\emptyset$ & $\emptyset$ & $\emptyset$ & $\emptyset$ \\
\hline v1 & $\varnothing$ & $\varnothing$ & $\emptyset$ & $\begin{array}{c}\mathrm{d} 1, \mathrm{~d} 2, \mathrm{~d} 3, \\
\mathrm{~d} 4, \mathrm{~d} 5\end{array}$ \\
\hline $\mathrm{f} 2$ & $\begin{array}{c}\mathrm{d} 1, \mathrm{~d} 2, \mathrm{~d} 3, \mathrm{~d} 4 \\
\mathrm{~d} 5\end{array}$ & $\varnothing$ & $\varnothing$ & d6,d7 \\
\hline v3 & $\begin{array}{c}\mathrm{d} 1, \mathrm{~d} 2, \mathrm{~d} 3, \mathrm{~d} 5 \\
\mathrm{~d} 7\end{array}$ & $\varnothing$ & d6 & $\begin{array}{c}\mathrm{d} 8, \mathrm{~d} 9, \mathrm{~d} 1 \\
0, \mathrm{~d} 11, \mathrm{~d} 1 \\
2\end{array}$ \\
\hline $\mathrm{f} 4$ & $\begin{array}{c}\mathrm{d} 5, \mathrm{~d} 8, \mathrm{~d} 9, \mathrm{~d} 1 \\
0, \mathrm{~d} 11\end{array}$ & $\varnothing$ & $\emptyset$ & d13 \\
\hline f5 & $\begin{array}{c}\mathrm{d} 8, \mathrm{~d} 9, \mathrm{~d} 10, \mathrm{~d} \\
11, \mathrm{~d} 12\end{array}$ & $\varnothing$ & $\emptyset$ & $\mathrm{d} 14, \mathrm{~d} 15$ \\
\hline v6 & $\begin{array}{c}\mathrm{d} 8, \mathrm{~d} 9, \mathrm{~d} 10, \mathrm{~d} \\
11, \mathrm{~d} 15\end{array}$ & $\varnothing$ & d14 & d 16 \\
\hline v7 & $\begin{array}{c}\mathrm{d} 8, \mathrm{~d} 9, \mathrm{~d} 10, \mathrm{~d} \\
11, \mathrm{~d} 15\end{array}$ & $\varnothing$ & d14 & d 17 \\
\hline $\mathrm{v} 8$ & d13 & $\varnothing$ & $\varnothing$ & d18 \\
\hline f9 & $\begin{array}{c}\mathrm{d} 1, \mathrm{~d} 2, \mathrm{~d} 3, \mathrm{~d} 8 \\
\mathrm{~d} 9, \mathrm{~d} 10, \mathrm{~d} 11 \\
\mathrm{~d} 12, \mathrm{~d} 16, \mathrm{~d} 1 \\
8\end{array}$ & $\varnothing$ & $\emptyset$ & d19 \\
\hline $\mathrm{e}$ & $\mathrm{d} 7$ & $\begin{array}{c}\mathrm{d} 8, \mathrm{~d} 9, \mathrm{~d} 10, \mathrm{~d} \\
11, \mathrm{~d} 12, \mathrm{~d} 13, \\
\mathrm{~d} 15, \mathrm{~d} 16, \mathrm{~d} 17 \\
\text {,d18,d19 }\end{array}$ & $\varnothing$ & $\varnothing$ \\
\hline
\end{tabular}


For example, $\lambda_{f 2}^{u}([d 1, d 2, d 3, d 4, d 5],[d 6, d 7])$ is an unconditional data dependency of $f 2 ; \lambda_{e}^{c}([d 8], \varnothing)$ is an conditional data dependency of $e$, which means $d 8$ is needed as the input data of $e$ only when the service request passes the check; $\lambda^{e}{ }_{v 3}([d 6]$, $[d 8, d 9, d 10, d 11, d 12])$ is an execution data dependency for $v 3$, which means $d 6$ determines whether to execute v3. Direct function object dependency are derived from above data dependency, including mandatory function object dependency and execution function object dependency (see Figure 4).For example, a mandatory dependency exists between $v l$ and $f 2$ because the input data $[d 1, d 2, d 3, d 4, d 5]$ of $f 2$ is the output data of $v 1$. And, an execution dependency exists between $f 2$ and $v 3$, because executing $v 3$ depends on whether $d 6$ meets the routing constraint, while $d 6$ is the output data of $f 2$.
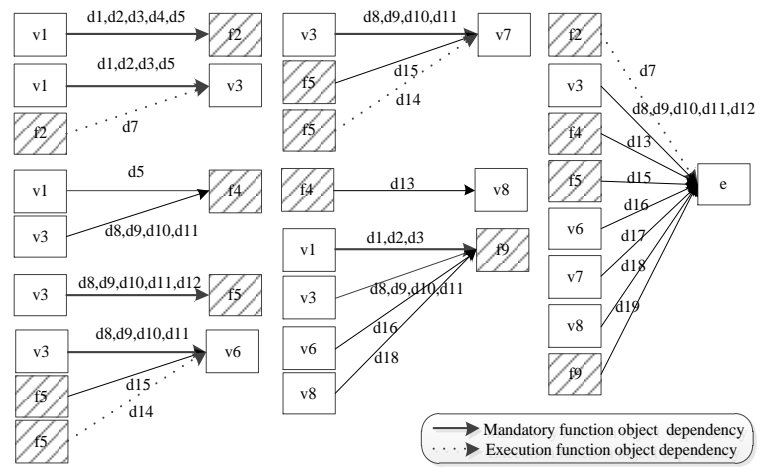

Figure 4. Function object dependencies of the toplevel platform

Table 4. Relation matrix between function objects

\begin{tabular}{|c|c|c|c|c|c|c|c|c|c|c|}
\hline & v1 & f2 & v3 & f4 & f5 & v6 & v7 & v8 & f9 & e \\
\hline v1 & NA & ${ }^{*}$ & & & & & & & & \\
\hline f2 & & NA & $>^{1}{ }_{\mathrm{C}}$ & & & & & & & $>^{2}{ }_{\mathrm{C}}$ \\
\hline v3 & & & NA & $*$ & $*$ & & & & & \\
\hline f4 & & & & NA & $\wedge$ & & & & & \\
\hline f5 & & & & $\wedge$ & NA & $>^{3}{ }_{\mathrm{C}}$ & $>^{3}{ }_{\mathrm{C}}$ & $*$ & & $>^{4} \mathrm{C}$ \\
\hline v6 & & & & & & NA & $\wedge$ & & $*$ & \\
\hline v7 & & & & & & $\wedge$ & NA & $\wedge$ & & $*$ \\
\hline v8 & & & & & & & & NA & & \\
\hline f9 & & & & & & & & & NA & $*$ \\
\hline
\end{tabular}

According to definition 5 to definition 10 in the WMDA method, acyclicity, well-connectedness, completeness and conciseness of dataflow are guaranteed [18]. Three types of function object relations are established by definition 14 in the WMDA method, such as the immediate precedence between $v 1$ and $f 2(v 1 * f 2)$ refers to $f 2$ executes immediately after the execution of $v 1$ without any other function objects between them, the conditional precedence between $f 2$ and $v 3\left(f 2>{ }_{C}{ }_{C} v 3\right)$ refers to $v 3$ executes only when the routing condition $c 1$ meets the condition, the AND-parallel exists between $f 4$ and $f 5$ $(f 4 \wedge f 5)$ refers to $f 4$ and $f 5$ executes simultaneously after the execution of $v 3$ because of $v 3 * f 4$ and $v 3 * f 5$. Then the relation matrix between function objects is completed (see Table 4). Finally, we build the workflow model for the top-level platform (see Figure $5)$.

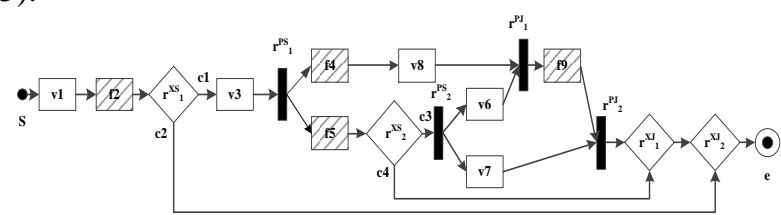

Figure 5. The workflow model of the top-level platform

\subsection{Step 2: Function object workflow modeling}

In the function object modeling, we focus on the specific implementation processes for each function pattern. Its modeling process strictly observes the procedures of WMDA. In addition, new data is admitted to produce within the function object model. For a special function pattern workflow modeling, the input data of all inner-function activities is from the input data of the function object or the new produced data, and the function object's output data is composed of the output data of activities.

As space is limited, we take the function pattern workflow modeling of structured request e-service as an example. As a running example, it includes the following activities. Firstly, application time and content are automatically checked by the platform whether they meet the basic service acceptance requirements. If they pass the check, this service request is accepted. Otherwise, it will be rejected. Secondly, categories and quantity of the service request materials are checked. If they pass the check, the service request would be standardized. Finally, the final service request check result is given, which may be the result that request is accepted and materials are approved or the result that request is accepted but materials are not approved or the rejection. Relevant activities and key data including the input data $[d 1, d 2, d 3, d 4, d 5]$ and output data $[d 6, d 7]$ of e-service function object $f 2$ are involved in this process (see Figure 6), routing constraints are shown in Table 5 and data dependencies of activities are shown in Table 6.

\begin{tabular}{|ll|}
\hline Activities: & Kev data: \\
v11: Check the application time; & d1: Service request ID; \\
v12: Check the application materials; & d2: Applier ID; \\
v13: Standardize the service request; & d3: Application time; \\
v14: Give the service request check result; & d4: Service request content; \\
& d5: Service request material; \\
& d6: Service request check result; \\
& d7: Standard service request content; \\
& d20: Check result of time; \\
& d21: Check result of material; \\
\hline
\end{tabular}

Figure 6. Activities and key data of the structured request e-service pattern 
Table 5. Routing constraints of the structured request e-service pattern

\begin{tabular}{|c|c|}
\hline Business rule & Routing constraint \\
\hline $\begin{array}{l}\text { If application time passes the check, the } \\
\text { service request is accepted and then its } \\
\text { application materials would be checked. }\end{array}$ & $\begin{array}{c}\mathrm{c} 21=\{\mathrm{d} 20=" Y \text { es" : } \\
\text { Execute(v22) }\}\end{array}$ \\
\hline $\begin{array}{l}\text { If application time doesn't pass the } \\
\text { check, the service request is rejected. }\end{array}$ & $\begin{array}{c}\mathrm{c} 22=\{\mathrm{d} 20=" \mathrm{No} ": \\
\text { Execute }(\mathrm{v} 24)\}\end{array}$ \\
\hline $\begin{array}{l}\text { If application materials pass the check, } \\
\text { the service request would be } \\
\text { standardized. }\end{array}$ & $\begin{array}{c}\mathrm{c} 23=\{\mathrm{d} 21=" Y e s ": \\
\text { Execute(v23) }\}\end{array}$ \\
\hline $\begin{array}{l}\text { If application materials don't pass the } \\
\text { check, the service request check result } \\
\text { would be given. }\end{array}$ & $\begin{array}{c}\text { c24=\{d21="No": } \\
\text { Execute(v24) }\}\end{array}$ \\
\hline
\end{tabular}

Table 6. Data dependencies of the structured request e-service pattern

\begin{tabular}{|c|c|c|c|c|}
\hline $\begin{array}{c}\text { Activity } \\
(\mathrm{V})\end{array}$ & $\begin{array}{c}\text { Unconditional } \\
\text { input data } \\
\left(\mathrm{I}^{u}{ }_{v}\right)\end{array}$ & $\begin{array}{c}\text { Conditional } \\
\text { input data } \\
\left(\mathrm{I}^{c}{ }_{v}\right)\end{array}$ & $\begin{array}{c}\text { Execution } \\
\text { input data } \\
\left(\mathrm{I}^{u}{ }_{v}\right)\end{array}$ & $\begin{array}{c}\text { Output } \\
\text { data } \\
\left(\mathrm{O}_{\mathrm{v}}\right)\end{array}$ \\
\hline $\mathrm{v} 21$ & $\mathrm{~d} 1, \mathrm{~d} 3, \mathrm{~d} 4$ & $\emptyset$ & $\emptyset$ & $\mathrm{d} 20$ \\
\hline $\mathrm{v} 22$ & $\mathrm{~d} 1, \mathrm{~d} 4, \mathrm{~d} 5$ & $\emptyset$ & $\mathrm{d} 20$ & $\mathrm{~d} 21$ \\
\hline $\mathrm{v} 23$ & $\mathrm{~d} 1, \mathrm{~d} 4$ & $\varnothing$ & $\mathrm{d} 21$ & $\mathrm{~d} 7$ \\
\hline $\mathrm{v} 24$ & $\mathrm{~d} 20, \mathrm{~d} 21$ & $\mathrm{~d} 20$ & $\emptyset$ & $\mathrm{d} 6$ \\
\hline
\end{tabular}

With the analysis of the data dependencies, activity dependencies are built (see Figure 7) and the relation matrix between activities is completed (see Table 7). Finally, we build the workflow model for the function pattern of structured request e-service (see Figure 8).

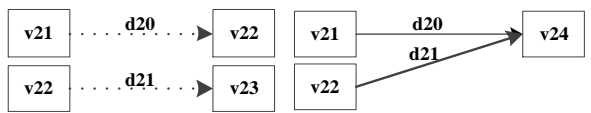

Figure 7. Activity dependencies of the structured request e-service pattern

Table 7. Relation matrix between activities of the structured request e-service pattern

\begin{tabular}{|c|c|c|c|c|}
\hline & v21 & v22 & v23 & v24 \\
\hline v21 & NA & $>^{21}{ }_{C}$ & & $*$ \\
\hline v22 & & NA & $>^{23}{ }_{C}$ & $*$ \\
\hline v23 & & & NA & \\
\hline v24 & & & & NA \\
\hline
\end{tabular}

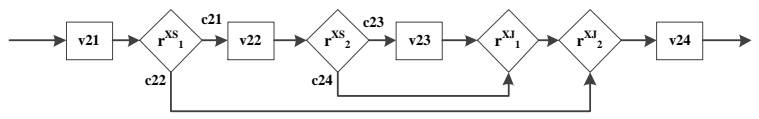

Figure 8. The workflow model of the structured request e-service pattern

Though the business processes are different in the terms of activities and data for other function patterns, their workflow models can be built in the same way like the above. During the modeling process, the most important thing is to ensure the input and output data of the inner-function activities to be limited to those of its function object that determined in the top-level platform workflow modeling. As a schema, we complete the workflow modeling of the most basic business process for each function pattern (see Figure 9).

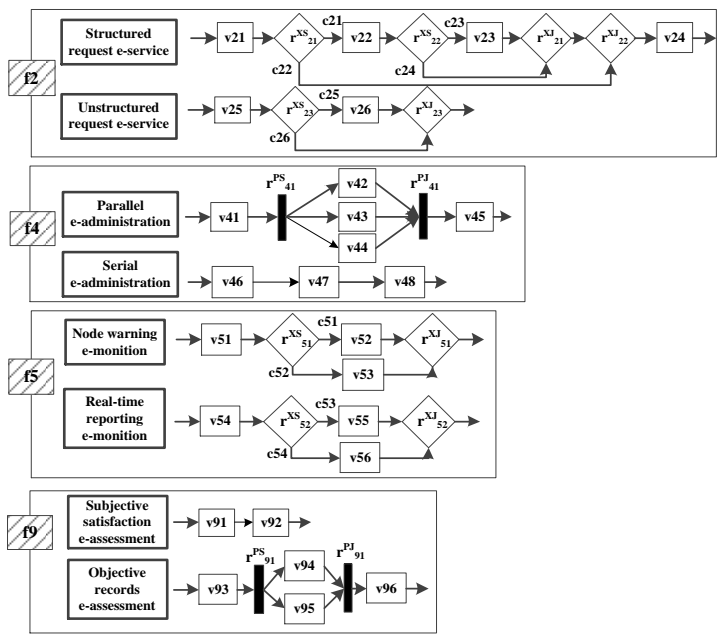

Figure 9. Workflow models of all function objects with two patterns

\section{An example of workflow modeling for the citizen appeal processing platform}

An example is introduced in this section to illustrate how the object-oriented workflow modeling schema is used for the collaborative e-governance platform. Because of the huge government system and indistinguishable department functions, most common citizens face the situation that they couldn't easily select the right departments to help them solve their problems once, and make any comment on the slow administrative processes and the satisfactory or unsatisfactory processing results. As a collaborative platform, citizen appeal processing platform has been attempted to be established in some developing countries' local governments to solve the problem. It is a one-stop, transparent and citizen engaging platform between government and citizens.

Generally there are five kinds of users on the platform including citizen, the integrated command department, the business department, the supervision department and the assessment department of government. For citizens, they propose the appeal in the form of text, photo, audio or video through the platform interface such as mobile APP, viewing the processing procedure and assessing the processing result. For the integrated command department, it checks and classifies the citizens' appeals, and transfers them to the relevant business department. They have the right to execute the end operation after the appeal is solved by the business department. For the business department, it exercises its function to deal with the administrative task corresponding to the appeal and submits the processing result to next department or back to the integrated command department. For the supervision department, it 
monitors the whole process from proposing appeal to executing the end operation and sometimes sends warning signals of timeout or irregularity to the business departments in their administrative process nodes. For the assessment department, it presents the performance evaluation of departments and civil servants in the accordance with platform data records and citizen's satisfaction evaluation.

In order to meet these requirements, the functions and their patterns of the citizen appeal processing platform are identified according to the function analysis in section 3 (see Figure 10). For the prior unidentifiable and undefinable appeal proposed by citizens, the pattern of unstructured request e-service is adopted by the integrated command department. As the processes have the characteristic of high pertinency for each appeal, the cooperation between several departments in a certain order in the form of serial eadministration is needed. The node warning e-monition is performed by the supervision department, while the real-time monitoring e-monition by citizens is not taken into account at the early development stage of platform with the possible reason of inadequate administrative regulation. For the assessment, both citizens' subjective satisfaction with the processing result and the assessment department's objective evaluation based on data are realized.

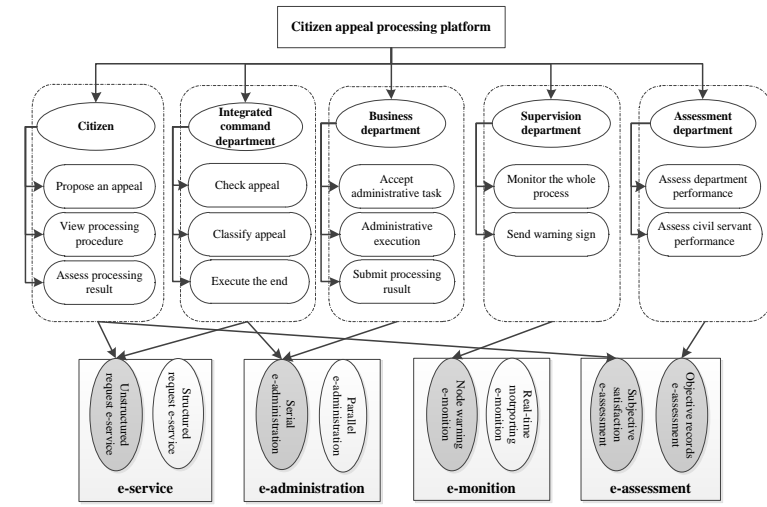

Figure 10. Functions and patterns of the citizen appeal processing platform

Next, we select the workflow models of identified function pattern in section 5.2 and integrate them into the top-level platform workflow model in section 5.1. In the process of integration, a bit of modification is needed to meet the actual demand. For instance, the integrated command department executes the end operation during the process of serial administration. So activity $v 49$ (Execute the end) is added into the $f 4$. In addition, the assessment department wants the available data used for performance assessment to extend to the data of citizen's satisfaction assessment. Therefore, the objective records e-assessment pattern follows the subjective satisfaction e-assessment pattern and its input and output data need to make some adjustments. Finally, the complete workflow model of the citizen appeal processing platform is established (see Figure 11).

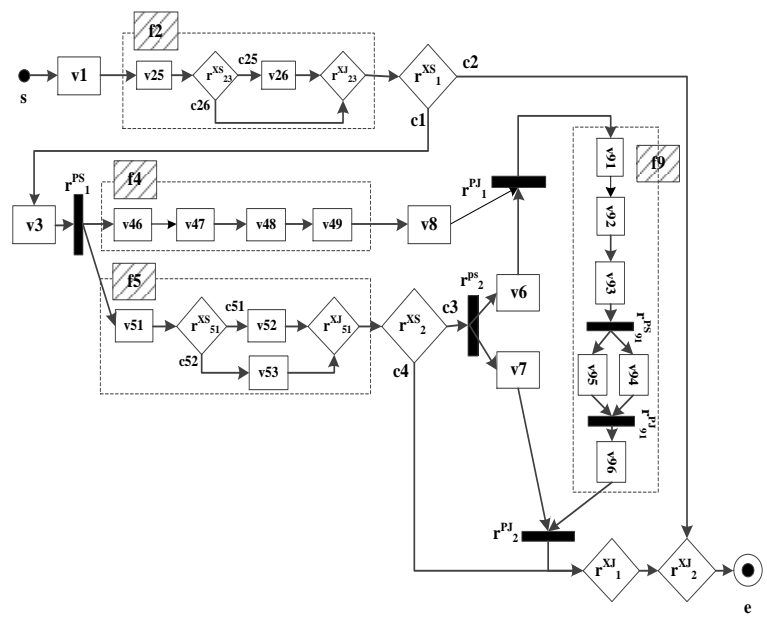

Figure 11. An example: the workflow model of citizen appeal processing platform

This example illustrates how the object-oriented workflow modeling schema is applied to an actual collaborative e-governance platform. The schema has three benefits. First, platform functions and their patterns in the continuous updating schema form a knowledge base, providing platform designers with more complete knowledge and clearer recognition for the platform-to-be-built instead of completely relying on the subjective intention. Second, it promotes the standardized, efficient and effective communication between business process analysts and technical developers. Based on the understanding of the basic schema, the analysts can specifically target to focus on the business process and data that need to be adjusted and the developers will have a clearer understanding of the requirements proposed by the analysts and then modify the relevant models. Third, the schema achieves reusability and easy modification of function models and improves the speediness and correctness of platform workflow modeling. A prototype workflow model for the platform can be quickly built with the reference of the existing and correct schema, which avoids some common dataflow errors and reduces the workload of modification and verification.

Due to space limitation, we only provide the example in one context. In addition, we only roughly describe the main business processes of citizen appeal processing and not further update the data in this special context. Our schema presents the most basic workflow models for the collaborative e-governance platforms in various contexts, which should embody more special platform requirements when it is used in one context. 


\section{Conclusions}

Developing countries are confronted to three challenges in designing and developing the collaborative e-governance platforms in different contexts, including common basic functions and patterns identification, a suitable workflow modeling method applying to the function-oriented and acrossorganization business process modeling and a unified development architecture. In order to address these challenges, we proposed an object-oriented workflow modeling schema using dataflow analysis to facilitate the platform development in different collaborative governance environments, based on the functions and their patterns analysis and an extended method of OOWMDA.

We claim three major contributions to the design and development of e-governance platforms. First, we provided an exploratory analysis of the most fundamental functions and their patterns for the platforms, including e-service with two patterns of structured request and unstructured request, eadministration in parallel or serial, e-monition with internal node warning pattern and external real-time reporting pattern, and e-assessment based on subjective citizens' satisfaction or objective platform data records. As a knowledge base enriched by subsequent studies, it informs the planners and designers what functions and patterns to select. Second, we proposed an extended method of OOWMDA, adding some key definitions like function object, function object data dependency and function object dependency. It not only avoids potential workflow model design errors like WMDA but also increases method operability and model reusability. It is suitable for function-oriented and multi-participant inter-organizational business process modeling like collaborative e-governance platform. Third, we proposed a two-step workflow modeling schema following OOWMDA, which is a rigorous and easy-use guideline for the system developers. It covers top-level platform workflow modeling based on function object dependencies using dataflow analysis and function objects workflow modeling based on activity dependencies using dataflow analysis. We also used citizen appeal processing platform as an example to illustrate how the schema promotes the platform workflow modeling. In such a context, the schema has three benefits: (1) providing designer with more complete knowledge for the platform-to-be-built; (2) facilitating effective communication between analysts and developers; (3) improving the speediness and correctness of platform workflow modeling.

However, this study also has some limitations. The first limitation is that the recognized four basic functions and their patterns may be insufficient along with the rapid development of the collaborative egovernance in different contexts for developing countries. The second limitation is that the platform workflow modeling as an exploratory work lacks validation of the used data and activities by comparing with the actual situation. The third limitation is that the extended method is applicable when the dataflow specification is well-connected, concise, complete and acyclic. In our future research, we would like to extend our work into two directions. First, we could select these typical contexts and carry out a case study to refine platform functions and their patterns in the basic schema. And a special modeling schema may be constructed in a certain context with higher complexity if necessary. Second, we could conduct field study to further evaluate our proposed workflow models and explore the usage of the object-oriented workflow modeling schema for the collaborative e-governance platform development.

\section{Acknowledgement}

This research was funded by the grants from the National Natural Science Foundation of China (\#71472053, \#71429001, \#71201039), and a grant from the Ph.D. Programs Foundation of Ministry of Education of China (\#20132302110017), and the grants from the Postdoctoral Science Foundation of China (\#2014M550198, 2015T80363).

\section{References}

[1] Kim P S, Halligan J, Cho N, et al. Toward participatory and transparent governance: report on the Sixth Global Forum on Reinventing Government [J]. Public Administration Review, 2005, 65(6): 646-654.

[2] Linders D. From e-government to we-government: Defining a typology for citizen coproduction in the age of social media [J]. Government Information Quarterly, 2012, 29(4): 446-454.

[3]Janssen M, Estevez E. Lean government and platformbased governance-Doing more with less [J]. Government Information Quarterly, 2013, 30: S1-S8.

[4] Lievens M. From government to governance: a symbolic mutation and its repercussions for democracy [J]. Political Studies, 2015, 63(S1): 2-17.

[5] Howlett M, Rayner J, Tollefson C. From government to governance in forest planning? Lessons from the case of the British Columbia Great Bear Rainforest initiative [J]. Forest policy and economics, 2009, 11(5): 383-391.

[6] McDermott P. Building open government [J]. Government Information Quarterly, 2010, 27(4): 401-413.

[7] Keohane, R. O. and Nye, J. S. Introduction, In Nye, J. S. and Donahue, J.D. (editors), Governance in a Globalization World. Washington, D.C.: Brookings Institution Press. 2000.

[8] Meijer A. E-governance innovation: Barriers and strategies [J]. Government Information Quarterly, 2015, 32(2): 198-206. 
[9] Dawes S S. The evolution and continuing challenges of egovernance [J]. Public Administration Review, 2008, 68(s1): S86-S102.

[10] Sun S X, Zhao J L, Nunamaker J F, et al. Formulating the data-flow perspective for business process management[J]. Information Systems Research, 2006, 17(4): 374-391.

[11] Noveck B S. Wiki government: how technology can make government better, democracy stronger, and citizens more powerful [M]. Brookings Institution Press, 2009.

[12] Janowski T. Digital government evolution: From transformation to contextualization [J]. Government Information Quarterly, 2015, 32(3): 221-236.

[13] Missingham R. E-parliament: Opening the door [J]. Government Information Quarterly, 2011, 28(3): 426-434.

[14] Bertot J C, Jaeger P T, Hansen D. The impact of polices on government social media usage: Issues, challenges, and recommendations [J]. Government information quarterly, 2012, 29(1): 30-40.

[15] Becker J, Algermissen L, Niehaves B. A procedure model for process oriented e-government projects[J]. Business Process Management Journal, 2006, 12(1): 61-75.

[16] Palvia S C J, Sharma S S. E-government and egovernance: definitions/domain framework and status around the world $[\mathrm{C}] / /$ International Conference on E-governance. 2007.

[17] Kim S, Lee J. E - Participation, Transparency, and Trust in Local Government [J]. Public Administration Review, 2012, 72(6): 819-828.

[18] Sun S X, Zhao J L. Formal workflow design analytics using data flow modeling [J]. Decision Support Systems, 2013, 55(1): 270-283.

[19] Bevir M, Rhodes R. Interpreting british governance [M] Routledge, 2003.

[20] Smith M J. From big government to big society: changing the state-society balance[J]. Parliamentary affairs, 2010, 63(4): 818-833.

[21] Schout A, Jordan A. Coordinated European Governance: Self-Organizing or Centrally Steered?[J]. Public Administration, 2005, 83(1): 201-220.

[22] Rossel P, Finger M. Conceptualizing egovernance[C]//Proceedings of the 1st international conference on Theory and practice of electronic governance. ACM, 2007: 399-407.

[23] Hood C, Heald D. Transparency: The key to better governance? [M]. Oxford University Press/British Academy, 2006.

[24] Grimmelikhuijsen S, Porumbescu G, Hong B, et al. The effect of transparency on trust in government: A cross national comparative experiment [J]. Public Administration Review, 2013, 73(4): 575-586.

[25] Reddick C G, Turner M. Channel choice and public service delivery in Canada: Comparing e-government to traditional service delivery $[\mathrm{J}]$. Government Information Quarterly, 2012, 29(1): 1-11.

[26] Pieterson W, Ebbers W, Van Dijk J. Personalization in the public sector: An inventory of organizational and user obstacles towards personalization of electronic services in the public sector [J]. Government Information Quarterly, 2007, 24(1): 148-164.

[27] Kuzma J M. Accessibility design issues with UK egovernment sites $[\mathrm{J}]$. Government Information Quarterly, 2010, 27(2): 141-146.
[28] Naik G, Joshi S, Basavaraj K P. Fostering inclusive growth through e-governance embedded rural telecenters (EGERT) in India [J]. Government Information Quarterly, 2012, 29: S82-S89.

[29] Dias G P, Rafael J A. A simple model and a distributed architecture for realizing one-stop e-government[J]. Electronic Commerce Research and Applications, 2007, 6(1): 81-90.

[30] Chen M, Zhang D, Zhou L. Empowering collaborative commerce with Web services enabled business process management systems[J]. Decision Support Systems, 2007, 43(2): 530-546.

[31] Stohr E A, Zhao J L. Workflow automation: Overview and research issues[J]. Information Systems Frontiers, 2001, 3(3): 281-296.

[32] van Der Aalst W M P, Ter Hofstede A H M, Kiepuszewski B, et al. Workflow patterns [J]. Distributed and parallel databases, 2003, 14(1): 5-51.

[33] Wang $\mathrm{H} \mathrm{J}$, Zhao J L. Constraint-centric workflow change analytics [J]. Decision Support Systems, 2011, 51(3): 562-575.

[34] Brambilla M, Ceri S, Fraternali P, et al. Process modeling in web applications[J]. ACM Transactions on Software Engineering and Methodology (TOSEM), 2006, 15(4): 360-409.

[35] Basu A, Blanning R W. A formal approach to workflow analysis[J]. Information Systems Research, 2000, 11(1): 1736.

[36] Dijkman R M, Dumas M, Ouyang C. Semantics and analysis of business process models in BPMN [J]. Information and Software Technology, 2008, 50(12): 12811294.

[37] Velte T, Velte A, Elsenpeter R C. Green IT: reduce your information system's environmental impact while adding to the bottom line[M]. McGraw-Hill, Inc., 2008.

[38] Dong M, Chen F F. Process modeling and analysis of manufacturing supply chain networks using object-oriented Petri nets $[\mathrm{J}]$. Robotics and Computer-Integrated Manufacturing, 2001, 17(1): 121-129.

[39] Secchi C, Bonfé M, Fantuzzi C, et al. Object-oriented modeling of complex mechatronic components for the manufacturing industry[J]. Mechatronics, IEEE/ASME Transactions on, 2007, 12(6): 696-702.

[40] Lee Y K, Park S J. OPNets: an object-oriented highlevel Petri net model for real-time system modeling [J]. Journal of Systems and Software, 1993, 20(1): 69-86.

[41] Wang L C. Object-oriented Petri nets for modelling and analysis of automated manufacturing systems [J]. Computer Integrated Manufacturing Systems, 1996, 9(2): 111-125.

[42] Carter L, Belanger F. Citizen adoption of electronic government initiatives[C]//System Sciences, 2004. Proceedings of the 37th Annual Hawaii International Conference on. IEEE, 2004: $10 \mathrm{pp}$.

[43] Reddick C G. A two-stage model of e-government growth: Theories and empirical evidence for US cities [J]. Government Information Quarterly, 2004, 21(1): 51-64.

[44] Zirtiloğlu H, Yolum P. Ranking semantic information for e-government: complaints management[C]//Proceedings of the first international workshop on Ontology-supported business intelligence. ACM, 2008: 5 .

[45] Layne K, Lee J. Developing fully functional Egovernment: A four stage model[J]. Government information quarterly, 2001, 18(2): 122-136. 